www.nature.com/pj

\title{
Effect of cooling rate after polymer melting on electrical properties of high-density polyethylene/Ni composites
}

\author{
Akihiko Kono, Naoko Miyakawa, Satoshi Kawadai, Yousuke Goto, Takeshi Maruoka, Masashi Yamamoto \\ and Hideo Horibe
}

We investigated the effects of cooling rate after polymer melting on the room temperature resistivity $\left(\rho_{L}\right)$ and on the positive temperature coefficient (PTC) effect of resistivity of high-density polyethylene (HDPE)/Ni conductive polymer composites. The $\rho_{\mathrm{L}}$ of slowly cooled samples was lower than that of quenched samples. It was hypothesized that slow cooling increases the crystallinity of HDPE, forming conductive paths as Ni particles localize in the amorphous matrix of HDPE. In the PTC effect, the inflection-point temperature of the PTC curve rose to the melting point of the HDPE with increasing Ni content. We speculated that the PTC effect of HDPE/Ni composites might occur by two mechanisms: cubical expansion of HDPE, and the diffusion of localized Ni particles into the amorphous matrix of HDPE as a result of the change from a crystalline matrix to an amorphous matrix on melting of HDPE.

Polymer Journal (2010) 42, 587-591; doi:10.1038/pj.2010.39; published online 19 May 2010

Keywords: amorphous matrix; conductive polymer composite; cooling rate; crystallinity; positive temperature coefficient effect

\section{INTRODUCTION}

Materials exhibiting a positive temperature coefficient (PTC) effect of resistivity are used in breakers to protect electronic circuits. The PTC effect implies that resistivity increases with rising temperature. Impurity-doped $\mathrm{BaTiO}_{3}$ exhibits the PTC effect. ${ }^{1-3}$ However, $\mathrm{BaTiO}_{3}$-based materials exhibit an NTC (negative temperature coefficient) effect immediately after the PTC effect. The NTC effect implies that resistivity decreases with rising temperature. It is thought that materials exhibiting an NTC effect are inappropriate for use in electronic circuit protection.

Conductive polymer composites ${ }^{4-9}$ with a conductive filler also exhibit the PTC effect. These composites are conventionally fabricated by filling carbon black (CB), metal powder or carbon nanotubes into a polymer matrix. Flexibility and processability are the advantages of these composites. To use conductive polymer composites in the protection of electronic circuits, both low resistivity at room temperature $\left(\rho_{\mathrm{L}}\right)$ and high resistivity at high temperature $\left(>100^{\circ} \mathrm{C}\right)$ are essential. In addition, it is essential that the NTC effect does not occur immediately after the PTC effect. To fabricate conductive polymer composites with these properties, it is necessary to clarify the physical mechanisms and their relation to the electrical properties of composites.

The $\rho_{\mathrm{L}}$ of conductive polymer composites filled with metal is $10^{-2} \Omega \mathrm{cm} .^{5}$ Percolation conduction, tunneling conduction and hopping conduction are considered as the electrical conduction mechanisms of conductive polymer composites. In particular, the low resistivity of conductive polymer composites with a large amount of conductive filler is explained by the percolation theory. ${ }^{8,10-16}$ Nakamura et al. ${ }^{16}$ reported that the change in $\rho_{\mathrm{L}}$ with increasing conductive filler content has two transition points and revealed that the conduction mechanism changes from a non-ohmic behavior to an ohmic behavior once the conductive filler content reaches the second transition point. ${ }^{16}$ They revealed that the critical filler content (percolation threshold), which forms a conductive path, is the second transition point. ${ }^{16}$

On the other hand, the resistivity at high temperature $\left(>100{ }^{\circ} \mathrm{C}\right)$ of conductive polymer composites reaches $10^{5} \Omega \mathrm{cm}$ even with a large amount of conductive filler. ${ }^{5}$ In particular, resistivity increases significantly after melting of the polymer. ${ }^{4,5}$

In a previous paper, we suggested that conductive fillers are localized in the amorphous matrix of the polymer. ${ }^{4}$ Thus, we assume that an investigation of the relationship between the electrical properties of composites and the crystallinity of the polymer is important.

In this paper, we discuss the effect of cooling rate after polymer melting on the electrical properties of HDPE/Ni conductive polymer composites prepared by the melt-blending method. We demonstrate that the $\rho_{\mathrm{L}}$ of the slowly cooled sample is lower than that of the quenched sample, because of increased crystallinity of the HDPE. Furthermore, we demonstrate that the PTC effect of the HDPE/Ni conductive polymer composites with a low $\mathrm{Ni}$ content occurs from the 
slight cubical expansion of the HDPE, whereas the PTC effect of the HDPE/Ni conductive polymer composites with a high $\mathrm{Ni}$ content occurs from both the drastic cubical expansion of the HDPE and the diffusion of localized Ni particles into the amorphous matrix of the HDPE, because of the change from a crystalline matrix to an amorphous matrix with the melting of the HDPE.

\section{EXPERIMENTAL PROCEDURE}

\section{Materials}

HDPE was used as a base polymer for conductive polymer composites, specifically, HJ560 manufactured by Japan Polyethylene (Tokyo, Japan). Its density was $0.964 \mathrm{~g} \mathrm{~cm}^{-3}$; its melting point was $135^{\circ} \mathrm{C}$; and its melt flow rate (temperature $190^{\circ} \mathrm{C}$, force $2160 \mathrm{~g}$ ) was $7 \mathrm{~g} / 10 \mathrm{~min}$. Ni particles manufactured by Inco (Toronto, Canada) were used as the conductive filler of the conductive polymer composites. Its density was $8.91 \mathrm{~g} \mathrm{~cm}^{-3}$, its particle size was $2.5 \mu \mathrm{m}$ and its resistivity was $7 \times 10^{-5} \Omega \mathrm{cm}$.

\section{Sample preparation}

HDPE pellets and Ni particles were melt blended at $200^{\circ} \mathrm{C}$ and at 60 r.p.m. for $15 \mathrm{~min}$, using a plastic mixing apparatus (Toyo Seiki 4M150; Toyo Seiki, Tokyo, Japan). The HDPE/Ni blend was inserted between the two $\mathrm{Fe}$ boards $\left(150 \mathrm{~mm} \times 150 \mathrm{~mm} \times 2.2 \mathrm{~mm}^{\mathrm{t}}\right)$ of a metallic mold and molded to a $1 \mathrm{~mm}$-thick board (sample) using the hot-press method. Prehot press was performed at $2.5 \mathrm{MPa}$ and at $200^{\circ} \mathrm{C}$ for $3 \mathrm{~min}$, and hot press was performed at $5 \mathrm{MPa}$ and $200^{\circ} \mathrm{C}$ for $4 \mathrm{~min}$. The sample in the metallic mold, after application of the hot press, was cooled in ice water (quench) or in air (slow cooling). Figure 1 depicts the sample temperature as a function of cooling time. The cooling time from 200 to $25^{\circ} \mathrm{C}$ (R.T.) for the quench method was $10 \mathrm{~min}$ and that of the slow cooling method was $45 \mathrm{~min}$.

\section{Characterization of the conductive polymer composite}

The $\rho_{\mathrm{L}}$ was measured by the four-point probe method. The probe distance was $5 \mathrm{~mm}$, and the applied current for measurements was $100 \mu \mathrm{A}$. The PTC effect was evaluated by measuring resistance using the two-terminal method while the sample was being heated in an oven at a rate of $1^{\circ} \mathrm{C} \mathrm{min}^{-1}$. In the two-terminal method, resistivity $\rho$ was calculated using equation $\rho=R S / d$ from the measured values of resistance $R$, sample area $S$ and sample thickness $d$. Sample area was $1 \mathrm{~cm}^{2}$ and sample thickness was approximately $0.5 \mathrm{~mm}$. To measure the resistance (resistivity) of the sample by the two-terminal method, Ni foil was heat sealed at $1 \mathrm{MPa}$ and at $200{ }^{\circ} \mathrm{C}$ for $5 \mathrm{~min}$ to form electrodes on both sides of the sample. The quenched sample, after the hot-press procedure, was again quenched after $\mathrm{Ni}$ foil lamination, and the slowly cooled sample, after the hot-

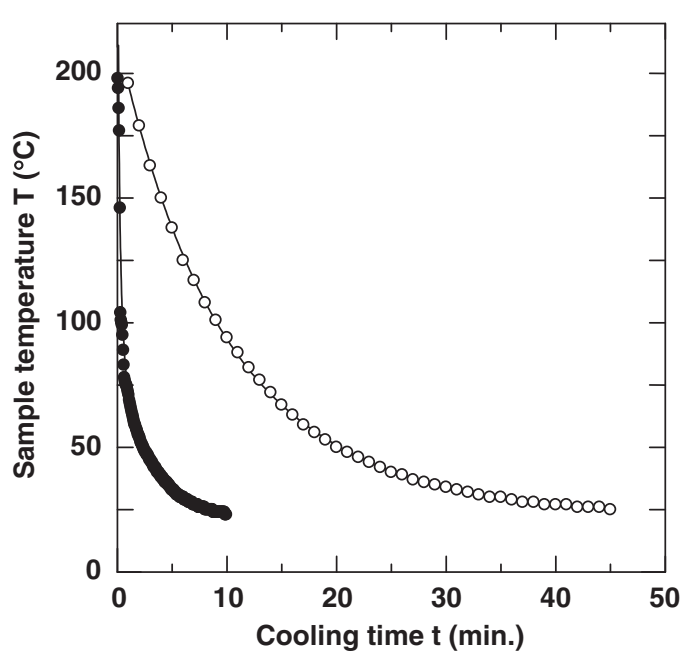

Figure 1 Change of sample temperature ( $T$ ) as a function of cooling time $(t)$. -: Quenching (in ice water). O: Slow cooling (in air). press procedure, was again cooled slowly after $\mathrm{Ni}$ foil lamination. The cooling method (quenching or slow cooling) of the sample after Ni foil lamination was the same as described in subsection 'Sample preparation'. The applied current for measurements was $100 \mu \mathrm{A}$ (when resistance is lower than $5 \mathrm{k} \Omega$ ), $12 \mu \mathrm{A}$ (when the resistance range is $5-50 \mathrm{k} \Omega$ ) and $1.2 \mu \mathrm{A}$ (when resistance is larger than $50 \mathrm{k} \Omega$ ). For the PTC effect of samples, we defined the inflection-point temperature of the PTC curve as the transition temperature. The crystallinity of HDPE was evaluated from the X-ray diffraction (XRD) spectrum of $30 \mathrm{kV}-15 \mathrm{~mA} \mathrm{CuK} \alpha$ radiation, using an XRD apparatus (Rigaku Mini Flex II; Rigaku, Tokyo, Japan).

\section{RESULTS AND DISCUSSION}

Relationship between cooling rate after polymer melting and crystallinity of the HDPE

Figure 2 plots the XRD spectra of the quenched pure HDPE board (Ni content $C_{\mathrm{Ni}}=0 \mathrm{wt} . \%$ ) and the slowly cooled pure HDPE board $\left(C_{\mathrm{Ni}}=0 \mathrm{wt} . \%\right)$. Sharp peaks from crystalline phases were observed in both the XRD spectrum of the quenched HDPE and that of the slowly cooled HDPE. To evaluate the crystallinity of the HDPE, the background and $\mathrm{Cu} K_{\alpha 2}$ peaks of the XRD spectrum (Figure 2) were separated by the Sonneveld-Visser method ${ }^{17}$ and the Rachinger method. ${ }^{18}$ The crystallinity of the quenched HDPE was $60 \%$ and that of the slowly cooled HDPE was $68 \%$. It was assumed that this difference was the result of the difference between cooling rate with the quench method and that with the slow-cooling method from the polymer melt.

We also investigated the crystallinity of the HDPE filled with various concentrations of Ni particles. Figure 3 illustrates the crystallinity of the HDPE in the quenched sample and that in the slowly cooled sample as a function of $C_{\mathrm{Ni}}$. The crystallinity of HDPE in both quenched samples and slowly cooled samples decreased with increasing $C_{\mathrm{Ni}}$. Ni particles interfered with the crystallization of HDPE.

\section{Resistivity of HDPE/Ni conductive polymer composites at room} temperature as a function of $\mathrm{Ni}$ content

Figure 4 presents the $\rho_{\mathrm{L}}$ value of the quenched sample and that of the slowly cooled sample as a function of $C_{\mathrm{Ni}}$. The $\rho_{\mathrm{L}}$ of the slowly cooled sample was lower than that of the quenched sample. In a previous paper, ${ }^{4}$ we suggested that $\mathrm{CB}$ particles in $\mathrm{HDPE} / \mathrm{CB}$ conductive polymer composites are localized in the amorphous matrix of the

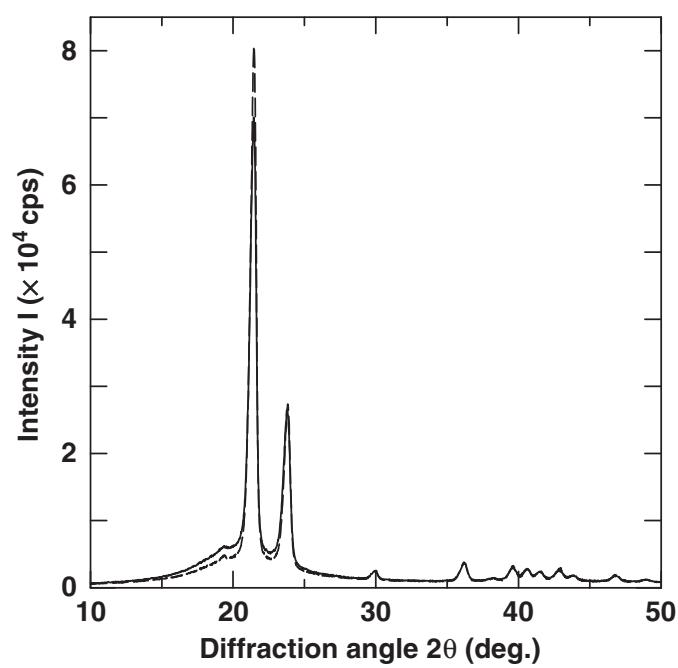

Figure 2 Typical XRD spectra of pure HDPE boards (Ni content=0 wt.\%). Solid line: Quenched HDPE. Dashed line: Slowly cooled HDPE. 


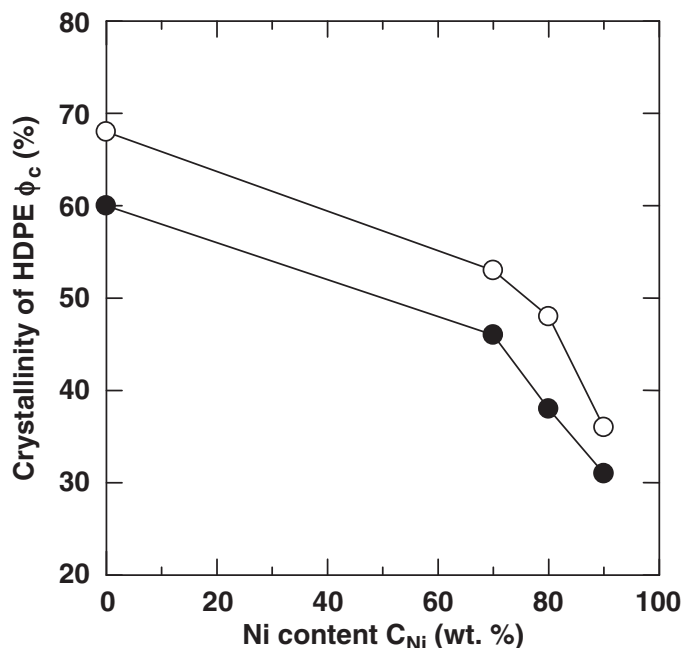

Figure 3 The change in crystallinity of HDPE as a function of Ni content $\left(C_{\mathrm{Ni}}\right)$. - : Quenched HDPE/Ni composites. O: Slowly cooled HDPE/Ni composites.

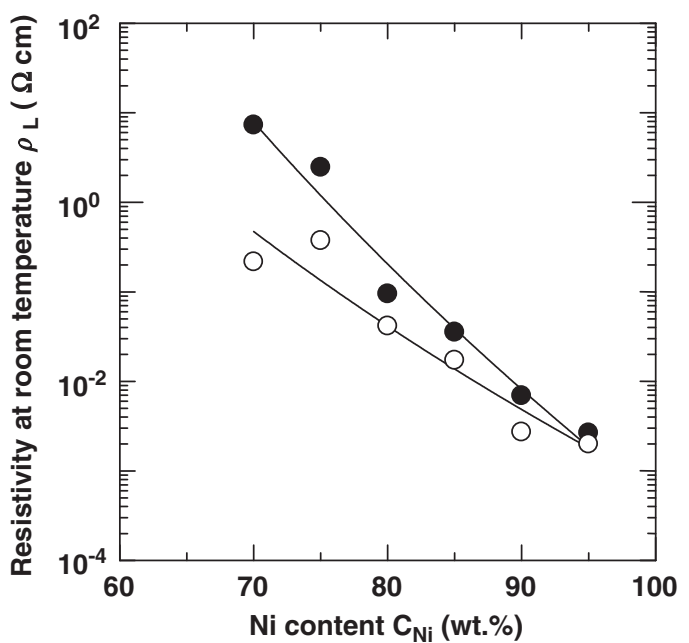

Figure 4 The change in $\rho_{L}$ of $\mathrm{HDPE} / \mathrm{Ni}$ composites as a function of $\mathrm{Ni}$ content $\left(C_{\mathrm{Ni}}\right)$. : Quenched HDPE/Ni composites. O: Slowly cooled HDPE/ Ni composites.

HDPE. On the basis of this suggestion, we assume that Ni particles in HDPE/Ni conductive polymer composites are localized into the amorphous matrix of HDPE. The conductive paths are likely formed by these localized Ni particles. Figures $5 \mathrm{a}-\mathrm{d}$ schematically illustrate the conductive path connection of the HDPE/Ni conductive polymer composite. Both crystallite size and thickness of the lamella are approximately tens of nanometers. ${ }^{19}$ On the other hand, the size of the average Ni particle is $2.5 \mu \mathrm{m}$. Therefore, it is thought that $\mathrm{Ni}$ particles are not in the crystalline matrix of the HDPE, but in the amorphous matrix of the HDPE. As indicated in Figures $5 a$ and $b$, the conductive path connection is facilitated by increased crystallinity of the HDPE. Consequently, it is suggested that $\rho_{\mathrm{L}}$ decreases with an increase in crystallinity of HDPE. Therefore, $\rho_{L}$ of the slowly cooled sample is lower than that of the quenched sample.

Figure 4 demonstrates that the slope of $\rho_{\mathrm{L}}$ change in the quenched sample is larger than that of the slowly cooled sample. In the slowly cooled sample, many conductive paths are formed, even with low $C_{\mathrm{Ni}}$ (70wt.\%), because the crystallinity of HDPE is high. Therefore, conductive paths grow less rapidly with increasing $C_{\mathrm{Ni}}$, and the slope of $\rho_{\mathrm{L}}$ change in the slowly cooled samples is small. On the other hand, quenched samples have few conductive paths when the $C_{\mathrm{Ni}}$ is low $(70 \mathrm{wt} . \%)$ because the crystallinity of HDPE in quenched samples is low. It is expected that conductive paths would grow rapidly with increasing $C_{\mathrm{Ni}}$. Therefore, the slope of $\rho_{\mathrm{L}}$ change in the quenched samples is large.

Figure 4 indicates that the difference between the $\rho_{\mathrm{L}}$ value of the quenched sample and that of the slowly cooled sample decreased with increasing $C_{\mathrm{Ni}}$. When $C_{\mathrm{Ni}}$ is high, it is assumed from Figures $5 \mathrm{c}$ and $\mathrm{d}$ that conductive paths are formed effectively, even with the low crystallinity of HDPE.

\section{PTC effects of HDPE/Ni conductive polymer composites}

Figure 6 plots the PTC curves of the quenched sample and of the slowly cooled sample as a function of $C_{\mathrm{Ni}}(70,80,90$ and $95 \mathrm{wt} . \%)$. When $C_{\mathrm{Ni}}<90 \mathrm{wt} . \%$, transition temperature decreases with decreasing $C_{\mathrm{Ni}}$. However, the transition temperatures of $C_{\mathrm{Ni}}=90 \mathrm{wt} . \%$ samples are consistent with those of $C_{\mathrm{Ni}}=95 \mathrm{wt} . \%$ samples.

In a previous paper, ${ }^{4}$ we investigated the PTC effect of the crystalline polymer/CB (for example, HDPE/CB, polypropylene/CB and syndiotactic-polystyrene/CB) conductive polymer composites and found that transition temperature corresponds to the melting point of the polymer. Consequently, it is thought that the PTC effect of HDPE/Ni conductive polymer composites occurs from melting HDPE. Conductive path disconnection by both the diffusion of the localized $\mathrm{Ni}$ particles in the amorphous matrix of HDPE because of the change from a crystalline matrix to an amorphous matrix and the drastic cubical expansion of $\mathrm{HDPE}^{20}$ are considered to be the mechanisms of the PTC effect observed during HDPE melt. In addition, the volume of HDPE expands slightly, even with temperatures below the melting point. ${ }^{20}$ This might contribute to the disconnection of the conductive paths. Thus, it is reasonable to consider that the origins of the PTC effect in HDPE/Ni conductive polymer composites arise both from the melting of HDPE and from the cubical expansion of HDPE.

It is assumed that the connection of $\mathrm{Ni}$ particles becomes weaker with decreasing $C_{\mathrm{Ni}}$. Therefore, lower $C_{\mathrm{Ni}}$ leads to the disconnection of conductive paths by smaller cubical expansions of the HDPE, and the transition temperature decreases with decreasing $C_{\mathrm{Ni}}$ when $C_{\mathrm{Ni}}<90$ wt.\%. In contrast, when $C_{\mathrm{Ni}} \geqslant 90 \mathrm{wt} . \%$, it is assumed that the conductive paths are not disconnected by the slight cubical expansion of the HDPE, because the conductive paths are more robust, formed by many Ni particles (see Figures $5 \mathrm{c}$ and $\mathrm{d}$ ). Therefore, conductive paths are disconnected by the melting of HDPE. Thus, the transition temperatures of $C_{\mathrm{Ni}}=90 \mathrm{wt} . \%$ samples are consistent with those of $C_{\mathrm{Ni}}=95 \mathrm{wt} . \%$ samples. It is clear from the result that the transition temperatures of samples at $C_{\mathrm{Ni}}=90$ and $95 \mathrm{wt} . \%$ are equal to the melting point of HDPE (see Figure 6).

Figure 6 demonstrates that the PTC curve of the slowly cooled sample is consistent with that of the quenched sample when $C_{\mathrm{Ni}}=80$, 90 and $95 \mathrm{wt} . \%$. In contrast, the PTC curve of the slowly cooled sample is not consistent with that of the quenched sample when $C_{\mathrm{Ni}}=70 \mathrm{wt} . \%$. We demonstrated in subsection 'Resistivity of HDPE/Ni conductive polymer composites at room temperature as a function of $\mathrm{Ni}$ content' that the localization of $\mathrm{Ni}$ particles decreases with decreasing crystallinity of HDPE. Therefore, we assume that the conductive paths of the quenched sample are more easily disconnected than those of the slowly cooled samples. Thus, the PTC curve of the slowly cooled sample is not consistent with that of the quenched sample when $C_{\mathrm{Ni}}=70 \mathrm{wt} . \%$. Moreover, we assumed that the influence of the crystallinity of HDPE on the connection of conductive paths 

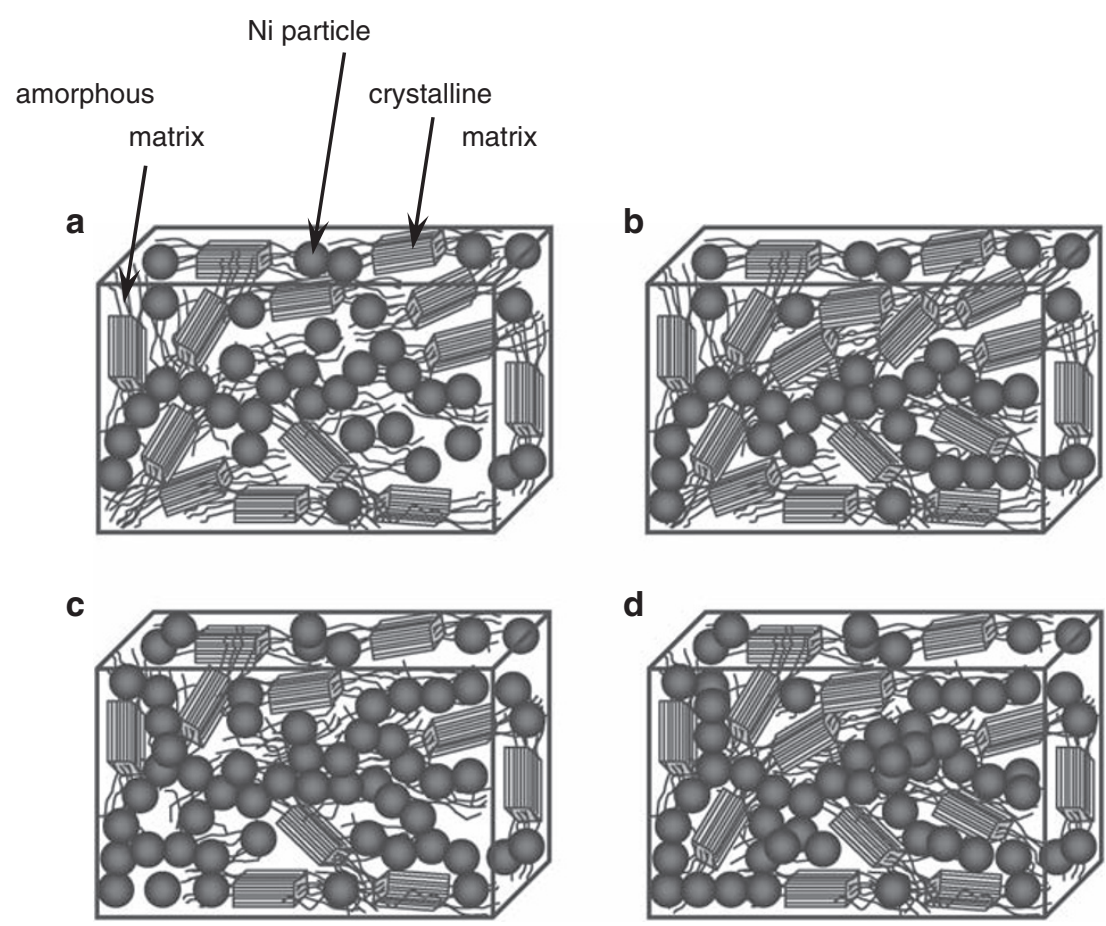

Figure 5 Schematic illustrations of the conductive path connection of HDPE/Ni composites. (a) Quenched HDPE/Ni composite with a small number of Ni particles. (b) Slowly cooled HDPE/Ni composite with a small number of Ni particles. (c) Quenched HDPE/Ni composite with a large number of Ni particles. (d) Slowly cooled HDPE/Ni composite with a large number of Ni particles.

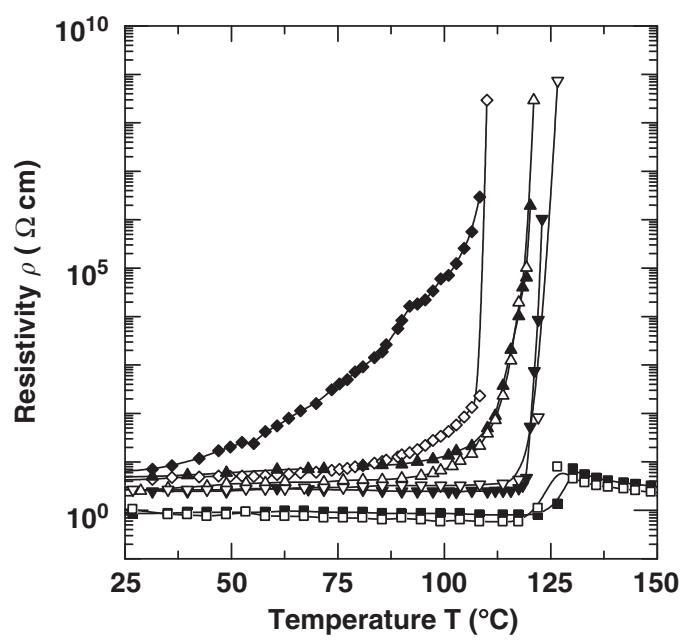

Figure 6 PTC curves of HDPE/Ni composites at various $\mathrm{Ni}$ contents $\left(C_{\mathrm{Ni}}\right)$. $\diamond: C_{\mathrm{Ni}}=70$ wt.\% (quench). $\diamond: C_{\mathrm{Ni}}=70 \mathrm{wt} . \%$ (slow cooling). $\boldsymbol{\Delta}: C_{\mathrm{Ni}}=80 \mathrm{wt} . \%$ (quench). $\triangle: C_{\mathrm{Ni}}=80$ wt.\% (slow cooling). $\mathbf{\nabla}: C_{\mathrm{Ni}}=90$ wt.\% (quench). $\nabla:$ $C_{\mathrm{Ni}}=90$ wt.\% (slow cooling). $\mathbf{\square}: C_{\mathrm{Ni}}=95 \mathrm{wt} . \%$ (quench). $\square: C_{\mathrm{Ni}}=95 \mathrm{wt} . \%$ (slow cooling).

becomes smaller with increasing $C_{\mathrm{Ni}}$ (see Figures $5 \mathrm{c}$ and $\mathrm{d}$ ). Therefore, the PTC curve of the slowly cooled sample is consistent with that of the quenched sample when $C_{\mathrm{Ni}}=80,90$ and $95 \mathrm{wt} . \%$.

Figure 6 indicates that both the quenched sample and the slowly cooled sample at $C_{\mathrm{Ni}}=95 \mathrm{wt} . \%$ exhibit the NTC effect. This suggests that Ni particles reassemble with decreased viscoelasticity after HDPE melting. ${ }^{21}$

\section{CONCLUSIONS}

We investigated the effect of cooling rate after polymer melting on the electrical properties of $\mathrm{HDPE} / \mathrm{Ni}$ conductive polymer composites prepared by the melt-blending method. It was assumed that conductive paths are formed by localized $\mathrm{Ni}$ particles in the amorphous matrix of HDPE. Conductive paths were formed effectively by increasing HDPE crystallinity. We demonstrated that HDPE/Ni conductive polymer composites with low $\rho_{\mathrm{L}}$ can be fabricated by slow cooling after polymer melting because the crystallinity of HDPE increases with slow cooling from the polymer melt. It was assumed that the PTC effect in HDPE/Ni conductive polymer composites occurs from cubical expansion of HDPE and diffusion of localized $\mathrm{Ni}$ particles into the amorphous matrix of the HDPE because of the change from crystalline to amorphous with the melting of the HDPE. The PTC effect of HDPE/Ni conductive polymer composites with a low $\mathrm{Ni}$ content results from the slight cubical expansion of HDPE, whereas the PTC effect of HDPE/Ni conductive polymer composites with a high Ni content results from both the drastic cubical expansion of HDPE and the diffusion of localized Ni particles in the amorphous matrix of HDPE, because of the change from a crystalline matrix to an amorphous matrix with HDPE melting.

1 Heywang, W. Resistivity anomaly in doped barium titanate. J. Am. Ceram. Soc. 47, 484-490 (1964).

2 Yamamoto, T. \& Takao, S. Complex impedance analysis of $\mathrm{Nb}$-doped $\left(\mathrm{Ba}_{0.6} \mathrm{Sr}_{0.4}\right) \mathrm{TiO}_{3}$ PTC (positive temperature coefficient) thermistors. Jpn. J. Appl. Phys. 31 (9b), 31203123 (1992).

3 Kim, D. H., Park, I. K., Um, W. S. \& Kim, H. G. Influence of microstructure and grain boundary potential barrier layer on the electrical breakdown of positive temperature coefficient $\mathrm{BaTiO}_{3}$ ceramics. Jpn. J. Appl. Phys. 34 (9A), 4862-4869 (1995).

4 Horibe, H., Kamimura, T. \& Yoshida, K. Electrical conductivity of polymer composites filled with carbon black. Jpn. J. Appl. Phys. 44 (4A), 2025-2029 (2005). 
5 Horibe, H., Kamimura, T. \& Yoshida, K. Electrical conductivity of polymer composites filled with metal. Jpn. J. Appl. Phys. 44 (6A), 4171-4175 (2005).

6 Chekanov, Y., Ohnogi, R., Asai, S. \& Sumita, M. Positive temperature coefficient effect of epoxy resin filled with short carbon fibers. Pol. J. 30, 381-387 (1998).

7 Chan, C. M. \& Cheng, C. L. Electrical properties of polymer composites prepared by sintering a mixture of carbon black and ultra-high molecular weight polyethylene powder. Polym. Eng. Sci. 37, 1127-1136 (1997).

8 Alig, I., Lellinger, D., Dudkin, S. M. \& Pötschke., P. Conductivity spectroscopy on melt processed polypropylene-multiwalled carbon nanotube composites: recovery after shear and crystallization. Polymer 48, 1020-1029 (2007).

$9 \mathrm{He}, \mathrm{X}$. J., Du, J. H., Ying, Z. \& Cheng, M. Positive temperature coefficient effect in multiwalled carbon nanotube/high-density polyethylene composites. Appl. Phys. Lett. 86, 062112-062114 (2005).

10 Pike, G. E. \& Seager, C. H. Percolation and conductivity: a computer study. I. Phys. Rev. B. 10, 1421-1434 (1973).

11 Balberg, I. Tunneling and nonuniversal conductivity in composite materials. Phys. Rev. Lett. 59, 1305-1308 (1987).

12 Sumita, M. \& Wu, G. Percolation structure control of nano-particles of fibers filled polymer composites. Seikei-Kakou 16, 762-767 (2004) (in Japanease).

13 Straley, J. P. Critical exponents for the conductivity of random resistor lattices. Phys. Rev. B 15, 5733-5737 (1977).
14 Weng, W., Chen, G. \& Wu, D. Transport properties of electrically conducting nylon 6/ foliated graphite nanocomposites. Polymer 46, 6250-6257 (2005).

15 Jeon, K., Lumata, L., Tokumoto, T., Steven, E., Brooks, J. \& Alamo, R. G. Low electrical conductivity threshold and crystalline morphology of single-walled carbon nanotubeshigh density polyethylene nanocomposites characterized by SEM, Raman spectroscopy and AFM. Polymer 48, 4751-4764 (2007).

16 Nakamura, S., Saito, K., Sawa, G. \& Snarskii, A. Critical exponent of conductivity and percolation phenomena of carbon black-polyethylene composites. Trans. IEEE Jpn. 117-A, 371-380 (1997) [in Japanese].

17 Sonneveld, E. J. \& Visser, J. W. Automatic collection of powder data from photographs. J. Appl. Crystallogr. 8, 1-7 (1975).

18 Klug, H. P. \& Alexander, L. E. X-ray Diffraction Procedures (Wiley \& Sons, New York, 1973) 2nd ed., p.625.

19 Murahashi, S., Kodaka, T., Kamachi, M. \& Norisue, T. Koubunshikagaku (KYORITSU SHUPPAN, Tokyo, 2009) 2nd ed., p.194. (in Japanese).

20 Hhao, L., Capt, L., Kamal, M. R. \& Choi, P. On the use of pressure-volume-temperature data of polyethylene liquids for the determination of their solubility and interaction parameters. Polym. Eng. Sci. 44, 853-860 (2004).

21 Alig, I., Skipa, T., Engel, M., Lellinger, D., Pegel, S. \& Pötschke, P. Electrical conductivity recovery in carbon nanotube-polymer composites after transient shear. Phys. Stat. Sol. B 244, 4223-4226 (2007). 